\title{
A aliança empresarial-militar e a ditadura brasileira: a atuação de empresários em escolas militares e de integrantes das forças armadas em companhias privadas durante o regime pós-1964
}

\author{
Pedro Campos \\ Claudio Beserra de Vasconcelos
}

\begin{abstract}
Resumo: $\mathrm{O}$ artigo analisa a aproximação entre militares e empresários e seu papel na definição da ditadura brasileira, inaugurada com o golpe de 1964. Para isso abordamos dois movimentos específicos. Em primeiro lugar, tratamos da presença de empresários brasileiros em escolas e instituições militares antes e durante a ditadura. Em seguida, problematizamos o emprego de militares em empresas privadas ao longo do regime. Defendemos que essa forma de aproximação tenha cumprido papel fundamental, já que expressa o conteúdo social e sentido máximo da ditadura - que por sua vez se apresenta, ao nosso ver, como um regime empresarial-militar. Para referendar nossa hipótese, usamos documentos do empresariado e dos arquivos militares que comprovam essa aliança, base do regime implantado no país desde 1964.
\end{abstract}

\begin{abstract}
The article analyses the rapprochement between the military and businesses, and its role in defining the Brazilian dictatorship, inaugurated with the 1964 coup. To this end, we tackle two specific movements. First, we deal with the presence of Brazilian businesspeople in military schools and institutions before and during the dictatorship. Then, we problematise the employment of military personnel in private companies throughout the regime. We argue that this form of approximation played a fundamental role in the regime, considering that it expresses the social content and utmost purpose of the dictatorship, which, in our view, presents itself as a businessmilitary regime. To endorse our hypothesis, we used documents from the business community and military archives, which prove this alliance - the basis of the regime implemented in the country since 1964.
\end{abstract}


O transcurso do governo Bolsonaro e as revelações da Comissão Parlamentar de Inquérito (CPI) da Pandemia da Covid no Brasil têm trazido à tona uma série de conexões entre militares e empresários envolvidos em negócios suspeitos, bem como a franca parceria entre integrantes das forças armadas com agentes de grupos econômicos, que demonstram afinidades e intenções práticas comuns. Essas situações têm suscitado no debate público um olhar sobre a longa história de parceria entre os integrantes da caserna com agentes empresariais, muitas vezes remontando à ditadura brasileira. No período, o envolvimento de militares com empresários, incluindo a relação com práticas espúrias, se multiplicou intensamente, tanto que houve uma operação para abafar a divulgação de episódios que pudessem comprometer a imagem das forças armadas.

Essa discussão tem permitido destacar leituras mais atualizadas, e que ganharam fôlego nos últimos, anos acerca do regime inaugurado com o golpe de Estado de 1964. Estas destacam justamente o perfil empresarial-militar da ditadura. Com base na pesquisa pioneira de René Armand Dreifuss (1981) ${ }^{1}$, alguns autores (Campos; Brandão e Lemos, 2020) têm insistido recentemente no caráter empresarial-militar não apenas do golpe que pôs fim ao regime democrático no país em 1964, como também do próprio regime político inaugurado com aquele episódio. Revelam-se, assim, o perfil de classe do governo encetado com a derrubada de João Goulart da Presidência da República e a ordem empresarial inaugurada a partir de então. Essa vertente rejeita as leituras de que tivemos uma ditadura exclusiva ou mesmo preponderantemente militar no país, em que os agentes das forças armadas lideravam sozinhos, ou quase, o processo político até a década de 1980. Por outro lado, afasta-se a ideia de um regime civil-militar no qual se supõe que a sociedade civil de forma ampla, genérica e amorfa tenha apoiado o golpe e regime com ele inaugurado, sem que se qualifiquem os segmentos específicos da formação social brasileira que endossaram e compuseram a ditadura, e dela se beneficiaram. Aceitamos a nomenclatura de regime civil-militar desde que o elemento civil seja entendido como dotado de classe, sendo o golpe e a ditadura um governo de força conduzido pela classe dominante².

\footnotetext{
${ }^{1}$ A obra de Dreifuss tem a marca da orientação de sua tese e inspiração teórica na obra de Ralph Miliband, que mescla conceitos de diferentes matrizes teóricas, como elite e classe dominante, de maneira original, provocativa e refinada. Sobre a obra do autor britânico, ver, por exemplo, Miliband (1972 [1970]).

${ }^{2}$ Nesse sentido, respeitamos, porém nos diferenciamos da perspectiva de autoras como Denise Rollemberg e Samantha Viz Quadrat no seu livro A construção social dos regimes autoritários. O trecho a seguir de ambas as autoras parece bem emblemático de um entendimento diametralmente oposto ao nosso: "Ainda pensando a América Latina, a democracia, que sempre enfrentou - enfrenta - dificuldades na região, paulatinamente deixou de ser vista por setores importantes da sociedade como a melhor maneira de combater o comunismo. Um governo forte, capaz de conter o avanço do perigo vermelho, sobretudo após a vitória da Revolução Cubana (1959), tornou-se a melhor ou a única saída possível. Os Estados Unidos, porta-vozes dos valores democráticos como meio de combate ao comunismo, aparecem no cenário como um dos principais incentivadores dos golpes e das ditaduras que se sucediam. Durante muito tempo, e ainda hoje - no meio político, no senso comum -, aos Estados Unidos foi atribuída a conta pelas ditaduras, especialmente nos casos brasileiro e chileno. Não negamos a influência estadunidense, seja por meio de suporte militar e/ou financeiro. Contudo, não lhe podemos atribuir toda responsabilidade sobre o que aconteceu. A América Latina tem sido compreendida como sem opção, explorada, à mercê dos interesses internacionais, ou seja, uma vítima através dos tempos. À região é atribuída
} 
Seguindo essa linha de análise, o propósito deste artigo é tentar avançar no processo de desvendamento e compreensão da forma como se deu a aliança entre empresários e militares. Esta aliança, conforme defendemos aqui, constituiu a base do regime inaugurado com o golpe de 1964. Nesse sentido, tratamos de dois fenômenos específicos. Por um lado, abordamos a presença de empresários em escolas e instituições militares antes e durante a ditadura brasileira. Fizemos um levantamento acerca dessa interação em arquivos militares, de modo a identificar o grau, as características e a intensidade da presença de agentes das empresas privadas em organizações como a Escola Superior de Guerra (ESG) antes e depois do golpe de 1964. Em seguida, analisamos a presença de militares nas empresas durante a ditadura. Com base em arquivos empresariais e em fontes secundárias, fizemos um levantamento de oficiais das forças armadas que atuavam em companhias privadas durante o regime, tentando identificar certas tendências, padrões e sentidos desse processo.

O texto se divide justamente nessas duas etapas. Na sequência, tecemos algumas considerações finais, buscando uma síntese e um balanço desses dois fenômenos, tentando avançar no processo de investigação e entendimento da própria ditadura.

\section{Empresários em escolas e instituições militares antes da ditadura:}

A relação entre militares e empresários não nasceu a partir da atuação da Escola Superior de Guerra (ESG). Ainda na primeira metade dos anos 1930, como menciona Maria Antonieta Leopoldi (2003, pp. 259-263), podemos observar a união entre militares e empresários, além de políticos nacionalistas, em torno do interesse comum em acabar com a concentração do setor de energia elétrica nas mãos de dois grupos estrangeiros: Brazilian Traction Light and Power e a American \& Foreign Power Company (Amforp). Um desses militares era o “tenente”3 Juarez Távora, então ministro da Agricultura do governo provisório e, posteriormente, comandante da ESG e responsável pela ampliação do acesso de civis aos cursos da instituição, além de ministro do primeiro governo da ditadura empresarial-militar. Com a intenção de alcançar o mencionado objetivo comum, em 1933, Távora criou o Departamento Nacional de Produção Mineral no seu ministério, com uma Diretoria das Águas, incumbida de fiscalizar as concessionárias.

\footnotetext{
uma história linear, sem cortes, desde a chegada dos europeus até o imperialismo americano. Suas sociedades seriam sempre manipuladas por governantes pouco preocupados com seus países. Não compartilhamos de maneira alguma dessas visões. [...] o autoritarismo foi desejado e alguns ditadores foram (são) queridos e percebidos como salvadores da pátria por pessoas e/ou segmentos da sociedade de todas as idades e origens sociais. O autoritarismo constituía elemento da cultura política de muitas sociedades." (Rollemberg e Quadrat, 2010, p. 22)

${ }^{3}$ O Tenentismo foi um movimento político-militar que ocorreu no Brasil entre as décadas de 1920 e1930. Embora tenha recebido essa denominação e os integrantes ficado historicamente conhecidos como "tenentes", nem todos os oficiais que compuseram as mobilizações tenenteistas possuíam essa patente.
} 
Poucos anos depois, já no contexto do Estado Novo (1937-1945), ocorreu uma comunhão de visões entre os engenheiros da Escola de Minas do Ouro Preto, políticos, empresários e militares especializados em engenharia de minérios (Leopoldi, 2003, p. 256). Dentre os militares, destaca-se a figura de Edmundo Macedo Soares e Silva, também "tenente", e defensor da industrialização do país com participação do capital privado, inclusive estrangeiro (Sá, 2008, p. 75). Durante a ditadura empresarial-militar, Macedo Soares foi ministro da Indústria e Comércio do governo Costa e Silva. Antes, em 1940, foi nomeado, junto com o empresário Guilherme Guinle, membro da Comissão Executiva do Plano Siderúrgico, responsável pelos estudos referentes à criação de uma companhia nacional de siderurgia. Das negociações dessa comissão com o governo dos Estados Unidos resultou o acordo, no qual o governo norte-americano, através do Eximbank (Banco de Exportação e Importação), possibilitou o montante necessário para a construção Companhia Siderúrgica Nacional (CSN), posteriormente presidida por Macedo Soares.

Porém, mais do que uniões esporádicas em torno de questões específicas, as proposições autoritárias presentes na Doutrina de Segurança Nacional (DSN) foram a base das teses desenvolvidas na ESG para todo e qualquer setor da realidade nacional. Tais proposições, no entanto, não se originam da criação dessa instituição; são anteriores a ela, revelando-se como um amálgama da relação entre militares e o empresariado desde os anos 1930.

O acordo entre Vargas e as FFAA em torno do Estado Novo, teve como resultado, por um lado, a consolidação dos militares como atores políticos, por outro, a promoção dos interesses da burguesia industrial emergente, em grande parte, através das novas frentes de atuação do empresariado no aparelho de Estado, via conselhos técnicos e comissões. Em paralelo, como bem observa Mendonça (1987, pp. 22-23), foi construído um discurso próprio que igualou a burguesia industrial brasileira às demais classes produtoras, e que se apropriou das categorias do discurso do pensamento político autoritário, também dominante entre os militares, especialmente em virtude da circulação da chamada Doutrina Góes Monteiro - para muitos, a antecessora da DSN da ESG (Coelho, 1976, p. 105). A ênfase no controle político, na integração nacional e na industrialização findou por reforçar a emergência do capitalismo industrial marcadamente elitista e autoritário. Em outros termos, podemos afirmar, como faz Ferraz (1997, p. 33), que a razão pela qual as teses desenvolvidas na ESG foram aceitas e difundidas por setores das elites brasileiras remonta ao pensamento autoritário típico do período compreendido entre as décadas de 1920 e 1940. Derivadas desse pensamento, as teses também serviram como ponto de união entre militares e empresários.

Portanto, não é possível dizer que a ESG foi a precursora nesse processo de aproximação entre elites civis, em particular, o empresariado, e militares. Tampouco ela foi a única ou a mais importante instituição na construção desse íntimo convívio. Contudo, criada em $1949^{4}$ com o

${ }^{4}$ A ESG foi instituída legalmente pelo decreto n. 25.705, de 22 de outubro de 1948, e criada, de fato, através da lei n. 
objetivo de assumir a função de um instituto nacional de altos estudos voltado para o desenvolvimento e consolidação de conhecimentos relativos ao exercício de funções de direção ou planejamento da segurança nacional, ${ }^{5}$ no contexto dos anos 1950, ela teve atuação efetiva no refinamento dessa relação, que é dotada de complexidades.

Já em sua carta de princípios, a ESG afirmava-se como locus ideal para preparação da elite responsável por assumir esse papel. O meio seria o hábito de trabalho em conjunto e uma "técnica racional de solução dos problemas", desenvolvida no interior da instituição (Sardenberg, 1971, p. 23). Com esse intuito, recebeu em seus cursos não só militares, mas também frações ascendentes da burguesia brasileira. Em pouco tempo, a escola tornou-se um centro não apenas de convívio, mas de fabricação de uma nova elite, articulada em torno de objetivos comuns. Desse modo, entendemos que a ESG exerceu o que René Armand Dreifuss (1986, p. 26-27) classificou como um “córtex político", por poder ser considerada um "núcleo da vanguarda político-intelectual" que visualizou e definiu objetivos estratégicos e táticos, e que, em especial, conectou atores de uma mesma classe, mas ideologicamente diversos, e mediou a relação entre eles, o que foi fundamental para a construção de uma unidade classista. De modo específico, a ESG difundiu entre seus estagiários a prática do trabalho em grupo e uma forma de análise da conjuntura, baseada em e determinada por uma série de conceitos previamente concebidos para construção e sustentação de uma doutrina e de uma política de segurança nacionais. Além disso, cumpriu papel importante na harmonização de teses e ideias em torno de proposta política específica, equilibrando a relação e, se não extinguindo, diminuindo possíveis receios existentes entre membros das Forças Armadas e frações da elite civil. Ao fim, possibilitou a convergência de necessidades variadas numa proposta de desenvolvimento para o Brasil. Mesmo que a conciliação total fosse uma utopia, a Escola unificou e difundiu um conjunto de aspirações de tipo capitalista e cujas bases foram, em grande parte, definidas ainda nos anos 1950.

A partir de dados obtidos em publicações da própria ESG, é possível identificar os elementos das frações burguesas que fizeram o Curso Superior de Guerra (CSG). Em termos quantitativos, entre 1950 e 1964, período de ingresso anterior à ditadura, dos 1374 estagiários, 542 eram civis. De modo ainda breve, podemos destacar alguns empresários que pertencem a tal grupo:

785, de 20 de agosto de 1949. BRASIL. Decreto n. 25.705, de 22 de outubro de 1948. Diário Oficial da União, Guanabara, DF, 25 nov. 1948, Seção 1, p. 15.479; BRASIL. Lei n. 785, de 20 de agosto de 1949. Diário Oficial da União, Guanabara, DF, 30 ago. 1949, Seção 1, p. 12.561.

5 BRASIL. Decreto n 27.264, de 28 de setembro de 1949. Regulamento da Escola Superior de Guerra. Diário Oficial da União, Guanabara, DF, 3 out. 1949, Seção 1, p. 14.098, artigo $1^{\circ}$. 
Campos, Pedro; Vasconcelos, Claudio Beserra de. A aliança empresarial-militar e a ditadura brasileira: a atuação de empresários em escolas militares e de integrantes das forças armadas em companhias privadas durante o regime pós-1964.

Quadro 1 - Empresários que participaram do Curso Superior de Guerra (1950-1964):

\begin{tabular}{|l|l|l|}
\hline Empresário: & Ano: & Origem / Organização a qual estava filiado: \\
\hline Alberto Jackson Byington Júnior - advogado & 1961 & Conselho Superior das Classes Produtoras \\
\hline Álvaro Portinho de Sá Freire - engenheiro & 1961 & Avulso \\
\hline Armando Daudt d'Oliveira - advogado & 1958 & Confederação Nacional do Comércio \\
\hline Celso Suckow da Fonseca - engenheiro & 1963 & Conselho Federal de Engenharia e Arquitetura \\
\hline Donald de Azambuja Lowndes - engenheiro & 1955 & Federação das Associações Comerciais do Brasil \\
\hline Glycon de Paiva Teixeira - engenheiro & 1954 & Academia Brasileira de Ciências \\
\hline Guilherme Júlio Borghoff - Empresário industrial & 1956 & Confederação Nacional do Comércio \\
\hline João Nicolau Mader Gonçalves - advogado & 1955 & Confederação Nacional do Comércio \\
\hline Jorge Bhering de Oliveira Mattos - advogado & 1960 & Conselho Superior das Classes Produtoras \\
\hline Jorge Eiras Furquim Werneck - engenheiro & 1961 & Sem identificação \\
\hline José Bento Ribeiro Dantas - advogado & 1958 & Sem identificação \\
\hline Luiz Gioseffi Jannuzzi & 1961 & Conselho Federal de Engenharia e Arquitetura \\
\hline Nelson Parente Ribeiro - banqueiro & 1961 & Associação Bancária do Rio de Janeiro \\
\hline Oscar de Oliveira - professor & 1953 & Clube de Engenharia \\
\hline Ruy Barreto - advogado & 1962 & Associação Comercial do Rio de Janeiro \\
\hline
\end{tabular}

Fonte: Ministério da Defesa. Almanaque dos Diplomados da Escola Superior de Guerra (1949 a 1999).

No geral, esse quadro com alguns nomes de empresários que foram alunos do CSG da ESG, lista homens ligados a associações de representação profissional ou econômica e que ocupavam cargos de destaque em empresas privadas no período anterior ao golpe de 1964. Como veremos, alguns dos citados atuaram diretamente no processo de desestabilização do governo João Goulart, alguns vieram a ocupar posições importantes na estrutura do aparelho de Estado durante o período da ditadura. Além disso, podemos perceber como há ligações posteriores desses homens em outras instituições. Vejamos a análise de alguns casos específicos que apresentam traços de similaridade em suas trajetórias.

O empresário industrial Guilherme Júlio Borghoff, diretor-presidente da Borghoff S.A Comércio e Técnica de Máquinas, Motores e Equipamentos, e também ligado à Remma S.A. Representações e Joseph Lucas do Brasil, Joseph Lucas Ind. - GB, pertenceu à turma de 1956 do Curso Superior de Guerra da ESG. Em sua identificação institucional, consta como sua entidade de origem a Confederação Nacional do Comércio (CNC). Ao final do curso, apresentou uma tese sobre comércio interno e externo. No ano seguinte, retornou à instituição como conferencista, palestrando 
sobre comércio interno. Além da CNC, foi membro da Associação Comercial do Rio de Janeiro, da Associação Nacional de Máquinas, Veículos e Peças e da Federation of the American Chambers of Commerce (Amcham), fórum político das corporações internacionais (Dreifuss, 1981, p. 95-96). Exerceu, ainda, a presidência da Associação dos Diplomados da ESG (Adesg), em 1958.

Todas essas associações tinham vínculos estritos com o Instituto de Pesquisas e Estudos Sociais (Ipes), do qual Guilherme Borghoff foi um dos fundadores, além de líder e conferencista. Pertenceu à unidade do Rio de Janeiro, exercendo funções no Conselho Orientador, Comitê Diretor e nos Grupos de Estudos e Ação. O empresário esteve diretamente envolvido na captação de fundos para o Ipes, e a própria Borghoff S.A. financiou o instituto. Também esteve integrado à unidade "Reforma Habitacional (Estudo econômico e legal sobre casas populares)", que conduziu em parceria com Sandra Cavalcanti (Campos, 2021, p. 248). Além do Ipes, foi membro da formação inicial do Instituto Brasileiro de Ação Democrática (lbad) (Dreifuss, 1981, p. 102)

Defensor e divulgador do "Rearmamento Moral", movimento de propaganda anticomunista, tratou do tema no interior da Associação Comercial do Rio de Janeiro e no próprio Ipes. No período anterior ao golpe de 1964, exerceu função executiva no "Comitê Revolucionário", estruturado em São Paulo em fins de 1961, reunindo militares e empresários (Ramírez, 2005, p. 294).

Durante o governo de Carlos Lacerda, no estado da Guanabara, ocupou o cargo de Secretário de Economia, entre 1963 e 1964, e foi presidente da Companhia de Progresso do Estado da Guanabara (Copeg) (Ramirez, 2005, p. 274). Ocupou cargos importantes durante os primeiros anos da ditadura empresarial-militar, sendo superintendente da Superintendência Nacional de Abastecimento (Sunab), entre 1964 e 1967, presidente da Comissão de Financiamento da Produção (CFP), entre 1964 e 1966, e da Comissão Nacional de Estímulo à Estabilização de Preços (Conep), entre 1964 e 1967, além de diretor da Cia Brasileira de Armazenagem (Cibrazem), em 1964 (Bortone, 2016, p. 19).

O advogado João Nicolau Mader Gonçalves mantinha ligações econômicas com a Químio Produtos Químicos Com. Ind. S.A., Laboratório Silva Araújo Roussel, Les Laboratoires Français Chimothérapie e com a Nuodex S.A. - Indústria e Comércio de Secantes. Pertenceu à turma de 1955 do CSG da ESG, e sua origem também consta como sendo a Confederação Nacional do Comércio. Ao fim do curso, produziu uma tese sobre padrões de consumo. Em 1968, presidiu a Adesg, e, em 1969, retornou à ESG para realizar uma conferência coletiva sobre "A iniciativa privada e a expansão dos mercados externo e interno". Além da CNC, estava ligado à Associação Nacional de Máquinas, Veículos e Peças (Anvap).

Fundador do Ipes e filiado à unidade do Rio de Janeiro, foi membro do Conselho Orientador Nacional. No contexto pré-golpe, como ativista desse instituto, organizou um encontro com parlamentares no Hotel Quitandinha, em Petrópolis, cujo objetivo era coordenar esforços e 
pressionar o sistema político. Durante a ditadura, foi assessor de administração do ministério da Fazenda, na gestão de Octávio Gouveia de Bulhões (Dreifuss, 1981, p. 429).

O advogado Jorge Bhering de Oliveira Mattos $^{6}$ era proprietário e diretor da Cia Bhering S.A. Sociedade Alimentícia, pertenceu à turma de 1960 do CSG da ESG, na qual consta sua origem como sendo o Conselho Superior das Classes Produtoras (Conclap). Presidente da Adesg em 1962, foi também diretor da Associação Comercial do Rio de Janeiro, presidente do Conclap e vice-presidente do Centro Industrial do Rio de Janeiro (Cirj).

Mattos apoiou o documento "Sugestões para uma política nacional de desenvolvimento", formulado pelo Conclap e entregue a Jânio Quadros logo após sua eleição, em 1960, reafirmando o papel da empresa privada e do capital estrangeiro no planejamento e desenvolvimento, e defendendo o controle da mobilização popular e da intervenção estatal na economia, a redefinição das funções do Estado, uma reforma da administração pública e a adoção de medidas contra a inflação.

Membro do grupo inicial do Ibad, também foi fundador do Ipes, estando ligado a unidade Ipes-GB. Nesse instituto, foi membro do Conselho Orientador Nacional e do Conselho Fiscal, além de atuar no processo de angariar fundos para o Ipes. Anticomunista declarado, foi ativo no movimento que culminou com o golpe de 1964, tendo patrocinado documentários produzidos pela Jean Manzon Films (Corrêa, 2005, p. 35). Após a instalação da ditadura, defendeu a candidatura do general Castelo Branco.

Outro advogado-empresário a destacar é José Bento Ribeiro Dantas, diretor-presidente da Serviços Aéreos Cruzeiro do Sul, que pertenceu à turma de 1958 do curso da ESG. Em 1966, realizou uma conferência na escola sobre "A expansão industrial brasileira". Foi ainda ligado ao Centro de Indústrias do Rio de Janeiro (Cirj), do qual foi presidente entre 1964 e 1966, e vice-presidente, de 1966 a 1969; foi fundador e presidente do Sindicato Nacional da Empresas Aéreas, e vice-presidente da Federação das Indústrias do Estado da Guanabara entre 1964 e 1969.

Fundador do Ipes e integrado à unidade do Rio de Janeiro, Dantas foi membro do Conselho Orientador. Como diretor da Cruzeiro do Sul, garantiu o transporte gratuito de membros do instituto para realização das suas atividades (Dreifuss, 1981, p. 204). Providenciou, ainda, que o documento LEEX - Lealdade ao Exército, texto que procurava harmonizar e coordenar as ações das diversas facções no interior das forças armadas, evitando ações e manifestações isoladas, fosse mimeografado nos escritórios da companhia (Dreifuss, 1981, p. 401, nota 21).

\footnotetext{
${ }^{6}$ Agradecemos a Renato Luís do Couto Neto e Lemos pela revisão e correção das informações sobre Jorge Bhering de Oliveira Mattos.
} 
Foi casado com Eudóxia Ribeiro Dantas, fundadora e vice-presidente da Campanha da Mulher pela Democracia (Camde), e assim como sua esposa, foi participante ativo do movimento político-militar que culminou com o golpe de 1964.

O banqueiro Nelson Parente Ribeiro foi diretor do Banco Irmãos Guimarães e do Ibec Empreendimentos, Administração e Investimentos, além de ligado à Associação dos Bancos do Estado de Guanabara e à Associação de Dirigentes Cristãos de Empresas - ADCE. Pertenceu à turma de 1961 do CSG da ESG, constando como sua origem a Associação Bancária do Rio de Janeiro. Também fundador do Ipes, foi dirigente e líder da unidade Ipes-GB, membro do Conselho Orientador e da unidade especial de opinião pública, criada para mobilização das camadas intermediárias - em particular, as donas de casa (Dreifuss, 1981, p. 342, nota 75).

O engenheiro e professor Oscar de Oliveira pertenceu à turma de 1953 do CSG da ESG, constando como sua origem na instituição o Clube de Engenharia. Em 1968, retornou à escola para uma conferência coletiva intitulada "Educação para o desenvolvimento e segurança". Era também ligado à Associação Comercial do Rio e à Associação Brasileira de Municípios (ABM). Foi ainda membro do conselho consultivo da Escola de Administração de Empresas da Fundação Getúlio Vargas (FGV) de São Paulo, superintendente do departamento de relações públicas da Companhia de Carris, Luz e Força do Rio de Janeiro (Light), além de ocupar vários cargos na Companhia Vale do Rio Doce a partir de 1954. Em 1959, passou a trabalhar na Companhia Auxiliar de Empresas de Mineração (Caemi). Em 1961, retornou à Vale do Rio Doce e foi, ainda, nomeado vice-presidente do Sindicato Nacional da Indústria de Extração de Ferro e Metais Básicos e presidente da Companhia Ferro e Aço de Vitória.

Assim como Jorge Bhering de Mattos, apoiou o documento "Sugestões para uma política nacional de desenvolvimento", formulado pelo Conclap e entregue ao recém-eleito presidente da República, Jânio Quadros. Também ativo participante do movimento que culminou com o golpe de 1964, é outro dos fundadores e líderes do Ipes, onde foi membro do Conselho Orientador e dos Grupos de Estudo e Ação. Filiado à unidade do Ipes-GB, também participou do Centro de Bibliotecnia, ligado ao Grupo de Publicações/Editorial e que tinha por missão a publicação e disseminação de livros infantis. Do mesmo modo que Nelson Parente Ribeiro, esteve integrado à unidade especial de opinião pública, criada para mobilização das camadas intermediárias, com foco nas donas de casa (Dreifuss, 1981, p. 342, nota 75). Além dessas atividades, esteve diretamente envolvido na captação de fundos para o Ipes, tendo lançado a ideia de criação de escritórios de consultoria, ligados ao instituto e com o objetivo declarado de "prestar serviços" a corporações privadas, e assim receber "pagamentos" que, de fato, visavam subsidiar o instituto. Atuou no sentido de desorganizar o movimento estudantil, participando de uma equipe do Grupo de Estudo e Doutrina, voltada para os "Problemas Universitários". Também participou diretamente da relação de colaboração entre o Ipes e a Camde. 
Em janeiro de 1965, assumiu a presidência da Companhia Vale do Rio Doce, permanecendo no cargo até o fim do governo Castelo Branco, em março de 1967. Durante esse período, presidiu também a Vale do Rio Doce Navegação (Docenave) e a Siderúrgica Vatu, subsidiárias da Vale do Rio Doce.

Não pretendemos, diante da exposição de tais casos, afirmar que a ESG foi a única ou a principal responsável pela construção de uma íntima relação entre o empresariado e os militares. Também esclarecemos que esse breve e introdutório levantamento de nomes e trajetórias não tem a intenção de dar conta desse complexo convívio nos anos anteriores ao golpe de 1964. É preciso dar continuidade à análise, abordando fatos relativos a outros empresários-estagiários e também a conferencistas, assim como às teses difundidas, mas esses são aspectos que extrapolariam os limites do presente artigo. Contudo, a partir da análise dos casos citados, cremos ser possível sustentar que a ESG, na evolução dos debates sobre segurança e desenvolvimento, contribuiu para unidade de pensamento e ação em torno de determinada proposta política de caráter capitalista. Ao reduzir as reservas e equilibrar as relações entre membros das Forças Armadas, frações burguesas e grupos alocados em diversos escalões da administração pública, a ESG promoveu a sociabilização interelites e contribuiu para a definição de uma ação política de classe e de um projeto de desenvolvimento integrado ao processo de expansão capitalista pós-Segunda Guerra. A escola forneceu fundamentos teóricos para avaliação das estruturas do Estado brasileiro e permitiu um determinado planejamento político e econômico de desenvolvimento do país, que foi sendo burilado ao longo dos anos nela e em outras instituições, como o CONCLAP e o Ipes. Um projeto burguês, autoritário, excludente e, no entanto, apresentado como demanda de toda a sociedade. Em síntese, a ESG funcionou como o locus onde parte da elite refletiu de maneira sistematizada, se autoconscientizou, estabeleceu projetos em seus múltiplos aspectos e se tornou crente de sua competência para administrar o país.

\section{Militares com cargos em empresas privadas durante o regime:}

O desempenho de atividades empresariais por parte de militares não é um processo exclusivamente posterior à ditadura. Ele é anterior ao golpe de 1964, e há vários casos que podem ser mencionados. Dreifuss (1981, p. 636) cita, por exemplo, a participação do brigadeiro Eduardo Gomes como um dos proprietários da construtora Kosmos e da empresa de engenharia Montreal, dentre vários outros militares que detinham ações de companhias privadas e que integravam os quadros do Instituto de Pesquisas e Estudos Sociais (Ipes). Muitos outros casos de empresários próximos de militares são citados no seu livro a partir dos documentos do Ipes, sendo diversos desses agentes ligados ao grande capital e relacionados a grupos econômicos internacionais.

Maria Victoria Benevides (1976, p. 147-193) chama a atenção para o fato de que outras agências do aparelho de Estado onde atuavam militares foram importantes canais de aproximação com empresários. Assim, funcionaram como pontes para interface entre esses agentes as empresas 
estatais e autarquias como Companhia Nacional de Álcalis (CNA), Petrobrás, Conselho Nacional do Petróleo (CNP), Rede Ferroviária Federal (RFFSA), Companhia Siderúrgica Nacional (CSN), Fábrica Nacional de Motores (FNM), Banco Nacional de Desenvolvimento Econômico (BNDE), Instituto Brasileiro do Café (IBC) e Instituto do Açúcar e do Álcool (IAA).

Nem todos os agentes empresariais que possuíam elos com militares estavam relacionados aos "internacionalistas" da Escola Superior de Guerra (ESG) e do Ipes. Eram muitos os empresários mais próximos dos integrantes das forças armadas conhecidos como integrantes da "linha dura" ou participantes do grupo dos chamados "nacionalistas autoritários" (Stepan, 1975 [1971], p. 166-183). O empresário Eduardo Marcondes Ferraz era próximo de integrantes desse grupo, que incluía os oficiais Jayme Portella e Arthur da Costa e Silva, militar que ele acolheu na noite do golpe de 1964 (Gaspari, 2002, p. 267-275). O dono da construtora carioca Sisal, Jadir Gomes de Souza, também tinha relações com Costa e Silva e com Antonio Gallotti (presidente da Light), com quem costumeiramente jogava cartas (Gaspari, 2002, p. 267-275). Costa e Silva cultivou uma relação próxima também com o médico e empresário carioca Leonel Tavares de Miranda e Albuquerque, dono da Casa de Saúde Dr. Eiras, e que se tornou ministro da Saúde após 1967 (Gaspari, 2002, p. 45-81). Também ligado ao chamado grupo dos nacionalistas autoritários, o empresário Armando Daudt de Oliveira (Biotônico Fontoura) era próximo do general Sylvio Frota, além de ter se relacionado com Carlos Lacerda e Samuel Wainer em suas ações na imprensa (Wainer, 1988 [1987]).

Outro caso notório de militar empresário era Edmundo de Macedo Soares e Silva. Este empresário passou pela diretoria de várias empresas como Companhia Siderúrgica Nacional (CSN), Companhia Siderúrgica Paulista (Cosipa), Mercedes-Benz, Acesita e outras. Após o golpe de 1964, ele foi imposto pela ditadura como o presidente da Confederação Nacional da Indústria (CNI), em substituição ao presidente da entidade, afinado com o governo João Goulart (Moraes, 2016, p. 6490).

Ao longo do regime, muitos militares foram empregados em empresas privadas e públicas. Uma função comum desempenhada por oficiais das forças armadas e das polícias dizia respeito ao aparato de segurança interna das empresas. Assim, era comum que militares e policiais ficassem responsáveis nas companhias pela vigilância, controle, espionagem e repressão contra os trabalhadores. A pesquisa de Marcelo Almeida Carvalho Silva (2018) mostra como o sistema de segurança industrial da Volkswagen do Brasil era feito pelo major Ademar Rudge, um militar que vigiava os operários da montadora e tinha livre trânsito pelo Departamento de Ordem Política e Social do estado de São Paulo (Deops). Documentos depositados no Arquivo Público do Estado de São Paulo (Apesp) atestam que no setor de segurança interna da multinacional alemã comandada por esse militar redigiam-se fichas dos operários e relatórios sobre as suas atividades políticas, documentos que eram repassados para o aparato oficial de repressão da ditadura. Pesquisa recente realizada por Richard Martins (2020) revela que várias empresas da região da cidade de São José dos 
Campos tinham práticas semelhantes, com seu aparato de segurança interno coordenado por militares.

No entanto, o emprego de militares em empresas não servia exclusivamente a propósitos de segurança e controle sobre os empregados da firma. Era comum que os grupos econômicos inserissem em seus quadros funcionais, e até de diretoria, integrantes das forças armadas, inclusive de alta patente. Alguns deles atuaram em postos elevados nessas companhias e chegaram a presidentes de empresas. Isso ocorria principalmente com militares de altas patentes, como coronéis e generais que antes haviam ocupado postos relevantes em agências do aparelho de Estado, como a direção de organismos públicos, ministérios ou funções relevantes em estatais. De acordo com um empresário que atuou naquele período, questionado sobre as dificuldades e especificidades de como se davam as relações com o governo de liderança militar durante a ditadura: "Isso é simples. A gente colocava um coronel na empresa." (Machado, 2010). De acordo com o dirigente da companhia de engenharia, a alocação de um funcionário de origem militar nos quadros da empresa privada durante o regime permitia facilidades junto ao aparelho de Estado e na interface junto a agências e agentes da estrutura estatal, podendo render bons frutos para a empresa.

Com base nas fontes primárias e secundárias que consultamos na pesquisa sobre as empresas, elaboramos um quadro não-exaustivo de militares empregados em companhias privadas durante a ditadura:

Quadro 1 - Militares com altas funções em empresas privadas durante a ditadura:

\begin{tabular}{|l|l|}
\hline Militar: & Empresa ou organização na qual trabalhou: \\
\hline marechal Ademar de Queiroz & Bakal (firma norte-americana de petroquímica) \\
\hline general Afonso Albuquerque Lima & Confecções Sparta e Sparta Nordeste \\
\hline almirante Álvaro Alberto & Rupturita (presidente; explosivos, 1971) \\
\hline general Artur Moura & Mendes Júnior S.A. \\
\hline filho do gal. Arthur da Costa e Silva & General Eletric do Brasil* \\
\hline general Carlos Luiz Guedes & Catermaq (presidente) em 1970* \\
\hline general César Cals Filho & Mineradora Centurião S.A. e outras empresas \\
\hline general Domingos Ventura Pinto Jr. & Construtora Rabello \\
\hline general Ernesto Geisel & Norquisa S.A. (presidente conselho de adm.) \\
\hline capitão Euclides Quandt de Oliveira & Siemens do Brasil (diretoria)* \\
\hline almirante Fernando Carlos de Mattos & Vice-presidente da Setal Engenharia em 1970 \\
\hline general Golbery do Couto e Silva & Dow Chemical (presidente) \\
\hline
\end{tabular}


Campos, Pedro; Vasconcelos, Claudio Beserra de. A aliança empresarial-militar e a ditadura brasileira: a atuação de empresários em escolas militares e de integrantes das forças armadas em companhias privadas durante o regime pós-1964.

\begin{tabular}{|l|l|}
\hline general Golbery do Couto e Silva & Banco Cidade \\
\hline major Heitor Aquino Ferreira & Projeto Jari e Boverj (assessor) \\
\hline coronel Hygino Corsetti & Nippon Eletric Corporation* \\
\hline gen. João Baptista Leopoldo Figueiredo & Caterpillar (conselho consultivo) $^{*}$ \\
\hline general Juracy Magalhães & Ericsson do Brasil (presidente) \\
\hline general Luiz Faro & Sinicesp (diretoria) \\
\hline coronel Mário David Andreazza & Companhia de Seguros Atlântica Boavista \\
\hline marechal Osvaldo Cordeiro de Farias & Grupo empresarial João Santos \\
\hline coronel Raimundo Saraiva Martins & Colméia Financeira \\
\hline
\end{tabular}

Fonte: Revista O Empreiteiro (1969); Revista O Empreiteiro (1970); Revista O Empreiteiro (1971); Revista O Empreiteiro (1985); Poças (2009); Gaspari (2003); Gaspari (2004); Bandeira, (1975); Fico (2008); Dreifuss (2009); SINICESP (2008); Paula (2000); D’Araújo; Castro (2008); Carvalho (2001); Abreu et al. (2001). * Firmas estrangeiras.

O quadro traz um levantamento não definitivo de um conjunto de oficiais, geralmente com patentes elevadas e posições relevantes na estrutura do aparelho de Estado, que desempenharam funções destacadas em empresas privadas durante o período da ditadura, a convite dos dirigentes desses grupos econômicos. Dos 21 casos listados, podemos ver como boa parte das empresas enumeradas era composta por firmas multinacionais, que possuíam uma força econômica e política significativa naquele período histórico. Além disso, dentre os militares que atuaram nessas empresas particulares, podemos perceber como predominam os agentes da força do Exército que tiveram cargos relevantes ou estiveram relacionados a pessoas que cumpriram funções de elevada importância nos governos da ditadura. Cabe, portanto, examinar alguns casos específicos que detêm destaque e inclusive ganharam notoriedade no período.

Um caso famoso é o do ex-ditador Ernesto Geisel, que, após deixar o cargo de presidente da República em 1979, conseguiu um emprego de elevada importância em uma companhia. Com larga experiência no ramo do petróleo, sendo também ex-presidente da Petrobrás, o general foi convidado para trabalhar na empresa Norquisa a partir de 1980, firma do ramo petroquímica indiretamente ligada à Petrobrás (Poças, 2009, p. 90-121). Geisel foi o primeiro presidente do Conselho de Administração da Norquisa, empresa que tinha participação da empreiteira Odebrecht e que era relacionada à grande burguesia baiana, relacionada aos grupos Clemente Mariani. Esse grande empresariado da Bahia ligado ao setor petroquímico foi chamado por Francisco de Oliveira (1998, p. 79-120) de grupo de Camaçari. Malu Gaspar (2020, p. 46-82) chama a atenção para a intensa proximidade do empresário Norberto Odebrecht com o ditador Ernesto Geisel.

Outro caso bastante notório é o do general Golbery do Couto e Silva, um dos principais nomes da ESG e do Ipes, fundador e primeiro dirigente do Serviço Nacional de Informações (SNI). 
Durante o período de marginalização política em meio ao governo Médici (1969-1974), foi convidado e cumpriu a função de presidente da filial da multinacional Dow Chemical do Brasil, por indicação de Ângelo de Calmon de Sá. A função lhe rendeu altos salários e muitas críticas de setores "ultranacionalistas" dentro das forças armadas. Além disso, José Carlos Assis (1984, p. 133-165) trouxe em seu livro uma denúncia de corrupção envolvendo a empresa durante o governo Geisel, quando Golbery cumpria a função de ministro-chefe da Casa Civil, e a transnacional norteamericana obteve do Ministério da Fazenda isenção de impostos para importar insumos petroquímicos, mesmo havendo produção nacional, em um momento em que a diretriz da política econômica era a de evitar compras no exterior de produtos como esse. A Companhia Brasileira de Estireno, produtora de insumos em Cubatão, fez um dossiê dos favorecimentos à Dow Chemical. Raphael de Almeida Magalhães fez denúncia na imprensa, e Roberto Saturnino Braga fez acusações sobre o caso no Senado Federal. A burocracia da Petrobrás era contra o projeto da Dow, e Hugo Abreu denunciou os benefícios à empresa no governo. O Estadão também criticou os favorecimentos à companhia norte-americana. A Dow Chemical queria instalar sozinha um polo cloroquímico em Aratu, ferindo o modelo tripartite do sistema petroquímico brasileiro, composto pela participação estatal, privada nacional e privada estrangeira. A DuPont entrou no país no modelo tripartite, aceitando-o, mas depois abandonou os investimentos, boicotando-os, dado que a Dow não seguia o modelo tripartite. A BEFIEX (Comissão para Concessão de Benefícios Fiscais a Programas Especiais de Exportação) negou o projeto da multinacional em Aratu, e esta desistiu do mesmo após o choque de 1979.

Outro alto quadro militar que atuou em empresas privadas é Heitor Aquino Ferreira. Apesar de não ser de uma patente elevada, chegando apenas a major na hierarquia do Exército, ele cumpriu funções muito relevantes durante o governo Geisel, sendo secretário pessoal do ditador e também do general Golbery do Couto e Silva, acumulando escritos sobre os bastidores do governo no período, que passaram à posse do jornalista Elio Gaspari. Ele atuou no projeto Jari, que era um conjunto de grandes investimentos realizados na região do Pará e do Amapá pelo empresário norteamericano Daniel Ludwig em parceria com as maiores empreiteiras brasileiras - Camargo Corrêa, Andrade Gutierrez, Mendes Júnior e Norberto Odebrecht - dedicado a produzir arroz e gmelina um insumo para produção de papel, - entre outras iniciativas (Gaspari, 2004, p. 197-213). Além dessa posição, Aquino também chegou a atuar na Bolsa de Valores da Cidade do Rio de Janeiro na segunda metade da década de 1980 (Dreifuss, 1989, p. 249-294).

Outras figuras associadas à condução da ditadura foram aliciadas para atuar em companhias privadas. Uma estratégia das empresas parecia buscar se aproximar e empregar parentes de figuras com muita relevância na administração pública. Assim, filhos de ditadores conseguiram cargos em grupos econômicos no período, o que poderia se relacionar à retribuição por ganhos e facilidades obtidos quando os ditadores cumpriram suas funções, bem como à intenção de se aproximar de 
figuras com trânsito no aparelho de Estado, que poderiam abrir portas e garantir benefícios para as companhias privadas, por sua vez dependentes do fundo público, de autorizações estatais para determinadas atividades ou de interesses diversos junto a agências estatais. A edição de outubro de 1985 da revista O Empreiteiro, por exemplo, trazia a informação de que João Baptista Leopoldo Figueiredo, parente do ex-ditador, cumpria naquele momento a função de presidente do Conselho Consultivo da Caterpillar do Brasil, maior fabricante de equipamentos para a indústria de construção em atividade no país (O Empreiteiro, 1985, p. 12). Jhonny, filho de Figueiredo, era genro de Ozório Paes Lopes da Costa, que foi sócio do bicheiro Castor de Andrade na Metalúrgica Castor. Em 1977, a empresa fornecia produtos de aço e metal, como camas, fogões e marmitas ao Exército. A empresa estava quebrada, mas uma operação arquitetada pelo SNI e apadrinhada pelo governo, conforme comprovam documentos disponíveis no Arquivo Nacional, forçou o grupo Coroa-Brastel a adquiri-la. Castor de Andrade tinha laços de amizade com a família do presidente. Ozório escreveu uma carta a Delfim demandando recursos públicos do BNDES, Banco do Brasil ou Caixa Econômica Federal para a metalúrgica (Jupiara e Otavio, 2016, p. 191-210). De forma semelhante, Carlos Fico (2008, p. 187-230) traz em seu livro a informação de que o filho do ditador Costa e Silva, Álcio da Costa e Silva, abandonou a carreira militar para trabalhar no setor privado, atuando na multinacional General Electric.

Outros altos nomes da ditadura estiveram empregados em empresas privadas após exercerem cargos em agências estatais. $\mathrm{O}$ ex-poderoso ministro do Interior Afonso Augusto de Albuquerque Lima, alcunhado como um militar da "linha dura" pelo grupo dos oficiais da ESG, reconhecido pela esquerda como um "nacionalista", defensor de políticas para a região da Amazônia quando atuou no governo Costa e Silva, e rival derrotado de Emílio Garrastazu Médici na indicação para a presidência da República em 1969, foi trabalhar no conglomerado econômico do cunhado (Gaspari, 2003, p. 369-398). Ele atuou como diretor-presidente da Confecções Sparta e da Sparta Nordeste, além de ser vice-presidente da União de Empresas Brasileiras, grupo econômico que sofreu intervenção e foi liquidado pelo Banco Central em 1977 (Dicionário Histórico-Biográfico Brasileiro Pós-1930, 2001).

Também o ex-ministro de Minas e Energia (1979-1985), o general do exército César Cals de Oliveira Filho, atuou em empresas privadas. De acordo com o Dicionário Histórico-Biográfico Brasileiro, ele manteve plantação de seringais e trabalhou na mineradora Centurião S.A. após exercer o cargo de ministro durante o governo Figueiredo. Além disso, seu filho atuava em uma empresa que recebia incentivos fiscais e financiamentos do Banco do Nordeste (Junqueira, 2001).

Outro ex-ministro de projeção na ditadura que foi atuar no setor privado após o fim do regime foi o ex-titular das pastas de Transportes (governos Costa e Silva e Médici) e do Interior (governo Figueiredo) Mário David Andreazza. Figura bastante poderosa na ditadura, ministro de projeção e agente próximo aos empresários, em particular os empreiteiros de obras públicas, 
Andreazza chegou a ser pré-candidato à Presidência da República nas prévias do PDS em 1984, mas saiu derrotado da disputa para o ex-governador Paulo Maluf, que foi , por sua vez, derrotado no colégio eleitoral por Tancredo Neves (PMDB). Além de nutrir intensa proximidade com companhias privadas, após abandonar as posições que mantinha no aparelho de Estado em meados da década de 1980, Andreazza trabalhou na Companhia de Seguros Atlântica Boavista (Paula, 2000, p. 341).

Por fim, mais um ex-ministro que desenvolveu carreira no setor privado foi o general Juracy Magalhães, que além de ter cumprido a posição de chanceler brasileiro durante a segunda metade do governo Castelo Branco (1964-1967), tinha uma longa história de interface junto a empresários. Gaspari (2003, p. 369-398) menciona que no início de sua carreira militar, Magalhães se aproximou do industrial Frederico Lundgren. Depois de deixar o Ministério de Relações Exteriores, foi convidado e aceitou ocupar a presidência da Ericsson do Brasil, filial da empresa sueca de comunicações e equipamentos eletrônicos (Bandeira, 1975, p. 155-182). Trata-se, assim, de mais um militar que assumiu a posição de mando de uma representante de uma companhia multinacional no Brasil.

Além desses militares que cumpriram posições de significativo destaque durante a ditadura, podemos verificar a presença de oficiais das forças armadas atuando no interior de empresas privadas ao longo do regime em diferentes segmentos econômicos. Dessa forma, em nossos estudos no ramo da indústria da construção notamos uma presença deliberada de agentes com origem na caserna em atividades no interior das construtoras e empresas de engenharia de uma forma geral. Temos a notícia através do livro do jornalista Elio Gaspari (2004, p. 279-305) que na década de 1970 o general Artur Moura atuava nos quadros funcionais da empreiteira Mendes Júnior, uma das maiores firmas de engenharia do país. Obtivemos uma notícia de jornal de São João del Rey que comprova que o general Domingos Ventura Pinto Jr. constava no quadro funcional da empreiteira mineira Rabello em 1970, fiscalizando o serviço de construção de uma estrada no interior do estado (Ponte da Cadeia, 1970). Através da revista O Empreiteiro, de setembro de 1969, ficamos sabendo também que o almirante Fernando Carlos de Mattos representava a empresa de engenharia Setal na diretoria da Associação Brasileira de Empresas de Montagem Industrial (Abemi), cumprindo a função de vice-presidente da entidade no período 1969-1970 (O Empreiteiro, 1969, p. 16). Outra associação empresarial do setor da indústria da construção que contava com militares em seus quadros funcionais era o Sindicato da Construção Pesada do Estado de São Paulo (Sinicesp), onde atuou por largo período o general Luiz Faro, sendo ele considerado uma das três figuras fundamentais no funcionamento do órgão de acordo com o seu livro de memória (Sinicesp, 2008, p. 18-27).

Em áreas próximas às empresas de construção, também vemos militares que atuaram em empresas privadas durante a ditadura. Temos a informação de que em 1970 o general Carlos Luiz Guedes atuava na Catermaq, empresa de vendas de máquinas e equipamentos Caterpillar para 
empresas construtoras (O Empreiteiro, 1970, p. 13). Já o coronel Raimundo Saraiva Martins, que chegou a cumprir a função de adido militar da embaixada do Brasil na França durante o governo Geisel, foi empregado no final da década de 1970 e início dos anos 1980 na companhia Colméia Financeira. O militar se notabilizaria no período como um dos denunciantes do relatório Saraiva, com a acusação contra o ministro Delfim Netto de cobrança de propina para intermediação de financiamentos franceses para o fornecimento de turbinas e equipamentos para hidrelétricas brasileiras da Cesp (Companhia de Eletricidade do Estado de São Paulo) e da Eletrobrás (Grael, 1985, p. 23-78).

Assim, esses casos parecem revelar a extensa presença de militares empregados em empresas privadas durante o período da ditadura. Importante reiterar que essa lista não é exaustiva e definitiva. Pelo contrário, trata-se de um levantamento preliminar obtido através da consulta de fontes primárias e secundárias que abordam as atividades empresariais durante o período ditatorial e que trazem apenas uma visão impressionista acerca do deliberado emprego de oficiais das forças armadas em grupos econômicos ao longo do regime. Por um lado, para os militares envolvidos, a atuação das empresas privadas configurava uma oportunidade para ganhos financeiros e recepção de elevados salários e cotas-partes da mais-valia gerada nessas empresas. Por outro, as empresas não empregavam esses integrantes da caserna simplesmente por competência profissional ou conhecimento sobre os ramos de atividade do grupo econômico, mas sim como mecanismo para obter facilidades de acesso às agências estatais em uma ditadura com grande ocupação de militares em postos de comando. Dessa forma, o militar dentro da empresa poderia conferir ao grupo econômico benefícios, facilidades, medidas oficiais de apoio, dentre outras formas de favorecimento. A presença desses oficiais nessas empresas não deixa também de expressar o próprio caráter do regime, com sua feição dominantemente empresarial-militar, que ficava exposta com essa política deliberada das empresas de indicar militares para seus postos funcionais.

\section{Conclusão}

É incorreto pensarmos que a relação entre militares e empresários durante a ditadura foi isenta de conflitos. Contudo, essa aproximação foi fundamental para a tomada do poder e para a definição do caráter da ditadura brasileira inaugurada com o golpe de 1964. A sociabilização entre esses atores em escolas e instituições militares durante os anos 1950 e 1960 foi essencial para dirimir receios mútuos, conciliar interesses diversos e homogeneizar uma proposta de transformação do Estado brasileiro. Por outro lado, a presença desses oficiais em empresas privadas no pós-1964 também ajuda a salientar o caráter empresarial-militar do regime.

Conforme vimos ao longo deste artigo, a aproximação entre militares e empresários antecede a ditadura implantada em 1964. A partir da atuação combinada em agências estatais, com a frequência de homens de negócios em escolas militares e interação nos cursos da ESG, agentes das 
forças armadas e do setor empresarial cultivaram um contato, desenvolvendo laços sociais, convergência de concepções de mundo, confluência de interesses e identidades no campo das ideias e das posições políticas. Assim, o próprio golpe de 1964 - pela composição de forças sociais responsáveis pela sua formulação e execução - resulta em boa medida dessa afluência entre empresários e militares, permitindo que o regime político inaugurado com a derrubada do sistema democrático tivesse a marca desses dois segmentos sociais e da própria união e interface entre eles. Assim, durante a ditadura, a relação dos empresários com os militares parece ter se consolidado e dado um salto qualitativo, alcançando em algumas ocasiões a configuração de sociedade de negócios entre agentes advindos das forças armadas e grupos econômicos. Nesse sentido, o emprego deliberado de militares de alta patente e ligados ao grupo dirigente da ditadura em empresas, em particular as de grande porte e atreladas ao capital estrangeiro, parece expressar a própria aliança que compunha o cerne da ditadura. A participação de militares nos negócios dos empresários diretamente ligados à ditadura parece, portanto, ter selado o acordo que dava base ao próprio regime.

\section{Referências}

Abreu, Alzira Alves de, Beloch, Israel, Lattman-Welman, Fernando e Lamarão, Sérgio Tadeu de Niemeyer (orgs.) (2001) Dicionário Histórico-Biográfico Brasileiro Pós-1930. Rio de Janeiro: FGV/CPDOC.

Assis, José Carlos de (1984) Os Mandarins da República: anatomia dos escândalos da administração pública (1968-1984). Rio de Janeiro: Paz e Terra.

Bandeira, Luiz Alberto Moniz (1975) Cartéis e Desnacionalização: a experiência brasileira, 1964-1974. Rio de Janeiro: Civilização Brasileira.

Benevides, Maria Victoria (1976) O Governo Juscelino Kubitschek: desenvolvimento econômico e estabilidade política, 1956-61. Rio de Janeiro: Paz e Terra.

Bortone, Elaine de Almeida (2016) 'A tomada do estado pelo Instituto de Pesquisas e Estudos Sociais (Ipes): o caso das empresas estatais federais do setor agrícola (1964-1967)', XVII Encontro de História da Anpuh-Rio - Entre o local e o global, Nova Iguaçu, Rio de Janeiro.

Campos, Pedro Henrique Pedreira, Brandão, Rafael Vaz da Motta e Lemos, Renato Luís do Couto Neto e (orgs.) (2020) Empresariado e Ditadura no Brasil. Rio de Janeiro: Consequência.

Campos, Pedro Henrique (2021) 'Interesses empresariais e a política de saneamento urbano durante a ditadura civil-militar brasileira (1964-1988): a construção da lógica dos grandes projetos e das grandes soluções', Revista Maracanan, Rio de Janeiro, n. 27, p. 240-260, maio/ago.

Carvalho, Luiz Maklouf (2001) Cobras Criadas: David Nasser e O Cruzeiro. 2a ed. São Paulo: EdSENAC-SP. 
Coelho, Edmundo Campos (1976) Em Busca de Identidade: o Exército e a Política na Sociedade Brasileira. Rio de Janeiro: Forense Universitária.

Corrêa, Marcos (2005) O discurso golpista nos documentários de Jean Manzon para o IPÊS (1962/1963). Dissertação de mestrado e Multimeios. Campinas, SP: Universidade Estadual de Campinas (UNICAMP), Instituto de Artes.

D’Araújo, Maria Celina; Castro, Celso (orgs.) (1997) Ernesto Geisel. $4^{\mathrm{a}}$ ed. Rio de Janeiro: EdFGV.

Dicionário Histórico-Biográfico Brasileiro Pós-1930. 'Lima, Albuquerque'. In: Abreu, Alzira Alves de, Beloch, Israel, Lattman-Welman, Fernando e Lamarão, Sérgio Tadeu de Niemeyer (orgs.) Dicionário Histórico-Biográfico Brasileiro Pós-1930. Rio de Janeiro: FGV/CPDOC. Disponível em: http://www.fgv.br/cpdoc/acervo/dicionarios/verbete-biografico/afonso-augusto-dealbuquerque-lima (acessado em 26 de julho de 2021).

Dreifuss, René Armand (1981) 1964: a conquista do Estado; ação política, poder e golpe de classe. Petrópolis: Vozes.

Dreifuss, René Armand (1986) A Internacional Capitalista: estratégias e táticas do empresariado transnacional - 1918-1986. Rio de Janeiro: Editora Espaço e Tempo.

Dreifuss, René Armand (1989) O Jogo da Direita na Nova República. 2ª ed. Petrópolis: Vozes.

Ferraz, Francisco César Alves (1997) À sombra dos carvalhos: Escola Superior de Guerra e política no Brasil: 1948-1955. Londrina: UEL.

Fico, Carlos (2008 [2008]) O Grande Irmão: da Operação Brother Sam aos anos de chumbo; o governo dos Estados Unidos e a ditadura militar brasileira. $2^{\underline{a}}$ ed. Rio de Janeiro: Civilização Brasileira.

Gaspar, Malu (2020) A Organização: a Odebrecht e o esquema de corrupção que chocou o mundo. São Paulo: Companhia das Letras.

GASPARI, Elio (2002) A Ditadura Envergonhada. São Paulo: Companhia das Letras.

GASPARI, Elio (2003) A Ditadura Derrotada. São Paulo: Companhia das Letras.

GASPARI, Elio (2004) A Ditadura Encurralada. São Paulo: Companhia das Letras.

GRAEL, Dickson M. (1985) Aventura, Corrupção, Terrorismo: à sombra da impunidade. Petrópolis: Vozes.

Junqueira, Eduardo (2001) 'Cals, César'. In: Abreu, Alzira Alves de, Beloch, Israel, Lattman-Welman, Fernando e Lamarão, Sérgio Tadeu de Niemeyer (orgs.) Dicionário Histórico-Biográfico Brasileiro Pós-1930. Rio de Janeiro: FGV/CPDOC. Disponível em: http://www.fgv.br/cpdoc/acervo/dicionarios/verbete-biografico/cesar-cals-de-oliveira-filho (acessado em: 16 de agosto de 2021)

Jupiara, Aloy, Otavio, Chico (2016) Os Porões da Contravenção: jogo do bicho e ditadura militar; a história da aliança que profissionalizou o crime organizado. Rio de Janeiro: Record.

Leopoldi, Maria Antonieta R. (2003) 'A economia política do primeiro governo Vargas (1930-1945): a política econômica em tempos de turbulência'. In Ferreira, Jorge e Delgado, Lucília A. N. [orgs.] 
(2003) O Brasil republicano. O tempo do nacional-estatismo: do início da década de 1930 ao apogeu do Estado Novo. Rio de Janeiro: Civilização Brasileira, pp. 241-283.

Machado, Carlos Freire (2010) Entrevista com o engenheiro Carlos Freire Machado, dirigente da empresa de engenharia STUP. Entrevista realizada no dia 18 de maio.

Mendonça, Sônia R. de (1987) Estado e Economia no Brasil: opções de desenvolvimento. Rio de Janeiro: Graal.

Miliband, Ralph (1972 [1970]) O Estado na Sociedade Capitalista. Rio de Janeiro: Zahar.

Ministério da Defesa (sem data) Almanaque dos Diplomados da Escola Superior de Guerra (1949 a 1999).

Moraes, Rafael (2016) 'O governo Castello Branco e a Federação das Indústrias do Estado de São Paulo: as bases do "milagre" (1964-1967)', América Latina en la Historia Económica. Mayo-agosto, p. 64-90.

Oliveira, Francisco de (1998) Os Direitos do Antivalor: a economia política da hegemonia imperfeita. Coleção Zero à esquerda. Petrópolis: Vozes.

Paula, Dilma Andrade de (2000) Fim de Linha: a extinção de ramais da estrada de ferro Leopoldina, 1955-1974. Tese de doutoramento em História. Niterói: UFF.

Poças, Bernardo Galheiro (2009) A Construção da Petroquímica no Brasil: sucessos e limitações. Monografia de final de curso de pós-graduação em Engenharia de Petróleo e Gás. Niterói: UFF.

Ponte da Cadeia (1970) ‘Rabelllo explica: a estrada é um fato’. Ponte da Cadeia. São João del Rey (MG) (1970, 147), 12 de abril, p. 1. Disponível em: http://memoria.bn.br/pdf/847550/per847550 1970 00147.pdf (acessado em 26 de julho de 2021).

Ramírez, Hérnan Ramiro (2005) Os institutos econômicos de organizações empresarias e sua relação com o Estado em perspectiva comparada: Argentina e Brasil, 1961-1996. Tese de doutorado em História. Porto Alegre: UFRGS.

O Empreiteiro (1969) 'Abemi', Revista O Empreiteiro (n.․2), setembro, p. 16.

O Empreiteiro (1970) 'Catermaq', Revista O Empreiteiro (n. 욱), novembro, p. 13.

O Empreiteiro (1971) 'Rupturita explosivos', Revista O Empreiteiro (n.o 43), agosto, p. 26.

O Empreiteiro (1985) Equipamentos Caterpillar. Revista O Empreiteiro (n.o 215), outubro, p. 12.

Rollemberg, Denise e Quadrat, Samantha Viz (2010) 'Apresentação'. In: Rollemberg, Denise e Quadrat, Samantha Viz (orgs.) (2010) A Construção Social dos Regimes Autoritários. legitimidade, consenso e consentimento no século XX. Vol. I - Europa. Rio de Janeiro: Civilização Brasileira.

Sá, Alexandre Avelar de (2008) 'O Exército e o desenvolvimento industrial no Estado Novo: a formação do Círculo de Técnicos Militares', Militares e Política, n.ํㅡ 2 (jan-jun.), p. 62-80.

Sardenberg, Idálio. 'Princípios Fundamentais da Escola Superior de Guerra', In: Fragoso, Augusto (1971) A Escola Superior de Guerra: evolução, atualidade, perspectiva. Presidência da República, Estado-Maior das Forças Armadas, Escola Superior de Guerra, C1-123-71, anexo n.o 1. 
Silva, Marcelo Almeida de Carvalho (2018) Estudos Organizacionais e Ditadura Brasileira: a normalização da violação dos direitos humanos por empresas durante o regime militar brasileiro. Tese de doutorado em Administração. Rio de Janeiro: PUC-Rio.

SINICESP (Luiz Roberto de Sousa Queiroz) (2008) A Saga da Construção Pesada em São Paulo. Vinhedo, SP: Avis brasilis.

Stepan, Alfred (1975 [1971]) Os Militares na Política: as mudanças de padrões na vida brasileira. Rio de Janeiro: Artenova.

Wainer, Samuel (1988 [1987]) Minha Razão de Viver. Rio de Janeiro: Record. 